\title{
Erratum to: Correlation of Contact Angle Hysteresis and Hydrodynamic Lubrication
}

\author{
L. Guo ${ }^{1}$ P. L. Wong ${ }^{1}$ F. Guo ${ }^{2}$
}

Published online: 30 July 2015

(c) Springer Science+Business Media New York 2015

\section{Erratum to: Tribol Lett (2015) 58:45 \\ DOI 10.1007/s11249-015-0518-1}

The original version of this article unfortunately contained an error in equation. The power of the numerator was incorrect in Eq. (4). The corrected version is given below:

$f(\theta)=\frac{(1+\cos \theta)^{1 / 2}}{(1-\cos \theta)^{1 / 6}(2+\cos \theta)^{4 / 3}}$

The online version of the original article can be found under doi:10. 1007/s11249-015-0518-1.

P. L. Wong

meplwong@cityu.edu.hk

1 Department of Mechanical and Biomedical Engineering, City

University of Hong Kong, 83 Tat Chee Avenue, Kowloon,

Hong Kong, People's Republic of China

2 School of Mechanical Engineering, Qingdao Technological

University, 11 Fushun Road, Qingdao 266033,

People's Republic of China 